\title{
Ensino de história frente às tecnologias digitais: um olhar sobre a prática
}

Teaching History versus Digital Technologies: A Look at Practice

\author{
Fabiano Viana Andrade*
}

Resumo

Considerando a importância da utilização pedagógica das Tecnologias Digitais de Informação e Comunicação (TDIC) como instrumento facilitador do processo de ensino-aprendizado, sobretudo no que se refere a uma formação docente que propicie essa potencial interação, o artigo analisa as TDIC utilizadas pelos docentes de História do Ensino Fundamental II, suas limitações e os conhecimentos necessários para seu uso. Para tanto, desenvolveu-se pesquisa qualitativa mediante aplicação de questionários a docentes da rede municipal de Campos dos Goytacazes (RJ). Os resultados descrevem dificuldades de acesso aos laboratórios de informática e falta de domínio das tecnologias, além da não utilização das tecnologias mais atuais, como redes sociais, celulares e tablets em sala de aula. Um fator positivo encontrado é que prevalece entre opiniões e comentários dos docentes uma visão favorável ao uso das TDIC. Palavras-chave: Ensino de História; TDIC; prática pedagógica.

\begin{abstract}
Considering the importance of the pedagogical use of Digital Information and Communication Technologies (TDIC) as a facilitator of the teaching-learning process, especially with regard to teacher training that fosters this potential interaction, the article analyzes the TDICs used by teachers of History of Elementary School II, its limitations and the knowledge required for its use. A qualitative research was developed through the application of questionnaires to teachers of the municipal network of Campos dos Goytacazes (RJ). The results describe difficulties in accessing computer labs and a lack of mastery of technologies, as well as the lack of use of the latest technologies such as social networks, cell phones and tablets in the classroom. One positive factor found is that a favorable view of the use of TDICs prevails among teachers' opinions and comments.

Keywords: History Teaching; TDIC; pedagogical practice.
\end{abstract}

\footnotetext{
* Mestre em Ensino de História pela Universidade Federal Fluminense (UFF), Niterói, RJ, Brasil. f.andrades@hotmail.com
} 
Diante dos avanços tecnológicos que permeiam o cotidiano dos jovens inseridos em ambientes educacionais, há um desafio por parte dos docentes, não só de inserir novas tecnologias em sala de aula, mas também de desenvolver práticas pedagógicas que promovam uma postura reflexiva sobre seu uso (Souza, 2009).

Sabe-se que à medida que as práticas pedagógicas tradicionalmente conhecidas dão lugar a novas formas de ensino e aprendizagem em meio à significativa inserção das Tecnologias Digitais de Informação e Comunicação (TDIC), processos de ensino e aprendizagem na sala de aula têm se tornado um desafio crescente e potencialmente inovador (Nunes, 2009). Em meio a essas mudanças, é importante reconhecer que as TDIC possuem grande contribuição metodológica e podem tornar-se ferramentas de apoio para a construção do conhecimento dos alunos, pois favorecem o desenvolvimento de uma série de capacidades ao permitir contato com ferramentas distintas como arquivos virtuais, sites, vídeos e jogos educativos, dentre outras (Moura, 2009). Entretanto, percebe-se ainda bastante resistência por parte dos docentes em relação ao uso das TDIC em sala de aula, ocasionada muitas vezes pelo fato de não terem tido formação sobre seu uso e, dessa forma, se sentirem despreparados (Damasceno; Brito, 2009).

Sobre essa temática, Rosa (2013) apresenta uma pesquisa com vinte docentes e destaca suas dificuldades em utilizar as TDIC em ambientes educacionais. $\mathrm{O}$ autor ressalta que a desconstrução desse paradigma é algo que deve emergir do próprio comportamento do docente, esforçando-se para vencer o receio e se permitindo usar as potencialidades oferecidas pelas TDIC em ambientes educacionais.

Já no início da atual expansão tecnológica, Prensky (2001) afirmava que a maioria dos docentes na época pertencia à geração antecessora à digital, de modo que se enquadravam como "imigrantes digitais". ${ }^{1}$ Diante dessa abordagem, o autor dividia a sociedade em duas novas ordens: os "nativos" e os "imigrantes digitais”. Segundo Mattos, Souza e Manhães (2012), a sociedade dos imigrantes digitais deixou marcas profundas como exclusão social e digital. Passada mais de uma década, percebe-se que os docentes ainda apresentam significativa resistência quanto ao uso das TDIC em sala de aula.

No contexto abordado por esses autores, a escola defronta-se com o desafio de trazer as informações presentes nas tecnologias, assim como as 
próprias ferramentas tecnológicas, articulando e influenciando o papel do docente no ambiente educacional (Porto, 2006) para que se possa atender à demanda dos "nativos digitais", considerando que o modelo tradicional se tornara incompatível com o novo perfil de aluno (Santos; Scarabotto, 2011).

Dessa forma, para que a fusão entre tecnologia e didática ocorra, é preciso desencadear um processo de transformação, que já ocorre atualmente em alguma medida e vem exigindo uma nova postura não apenas do docente, mas de todo o sistema educacional em relação ao uso das TDIC. É de suma importância que o profissional docente esteja em constante aperfeiçoamento, principalmente no que se refere à utilização de recursos tecnológicos como ferramentas facilitadoras no processo de ensino e aprendizagem (Souza, 2009; Lima, 2012), bem como se comprometa a modificar tal processo ativamente, com vistas a obter vantagem mútua das novas tecnologias na escola.

Sendo assim, é preciso compreender que os alunos não são os únicos aprendizes, e que eles próprios, os docentes, precisam estar preparados para ajudar os cidadãos da sociedade futura a entender as novas tecnologias e suas implicações de forma ampla (Nascimento, 2012), tornando o ensino e o aprendizado mais descomplicados, completos e compatíveis com seu tempo.

No que se refere a Campos dos Goytacazes, o município tem cerca de 500 mil habitantes (IBGE, 2010), e localiza-se no interior do estado do Rio de Janeiro, sendo fortemente marcado por baixos índices educacionais. No ano de 2011 atingiu apenas 3,4 pontos de acordo com os dados do Índice de Desenvolvimento da Educação Básica (Ideb) nos anos finais do Ensino Fundamental ( $6^{\circ}$ ao $9^{\circ}$ ano), quando a média nacional para tais séries foi de 4,1 pontos (Ideb, 2011). Quando comparada a todas as outras cidades do estado do Rio de Janeiro, Campos dos Goytacazes atingiu o índice mais baixo de educação. Esse é um dado importante e justifica estudos que visem identificar e problematizar questões pedagógicas como o uso das TDIC nas escolas, por exemplo.

Partindo desse princípio, o presente trabalho buscou analisar quais as TDIC utilizadas pelos docentes de História do Ensino Fundamental II da rede municipal de Campos dos Goytacazes em sua sala de aula, aspectos sobre sua formação curricular e extracurricular, suas dificuldades na utilização dessas ferramentas e quais as tecnologias mais utilizadas, além de suas preferências tecnológicas para uso didático no ensino de História. 
Para tanto, elaborou-se um questionário que foi aplicado aos docentes de $72,2 \%$ do total de escolas municipais da área central, onde foram aplicados questionários a 20 docentes (com retorno de 18) que lecionam a disciplina de História para uma ou mais séries entre $6^{\circ}$ e $9^{\circ}$ ano no período de julho a outubro de 2013. O questionário contou com perguntas abertas e fechadas, visando coletar as opiniões dos docentes entrevistados e obter informação de diferentes naturezas, como tempo de formação, conhecimento e uso sobre as TDIC, oferta de recursos tecnológicos nas escolas e tecnologias móveis, entre outros.

\section{O ENSINO DE HISTÓRIA E AS POSSIBILIDADES DA TDIC}

Já na primeira metade do século XX, estudiosos apontavam o fato de o ensino de história viver uma crise resultante, sobretudo, dos descompassos entre as inúmeras e diferentes demandas sociais e a instituição escolar, incapaz de atendê-las ou, até mesmo, de respondê-las de forma coerente (Nadai, 1996).

É consenso entre pesquisadores que o currículo de história ensinado no Brasil pouco dialoga com a realidade cultural dos alunos (Fonseca, 2009; Caimi, 2013; Oriá; 2005; Oliveira, 2012; Karnal, 2004). O que, de certa forma, gera uma rejeição por parte do alunato, e frases como "Em História pouca coisa nos interessa"; "Eu só decoro na hora da prova"; "Queremos coisas atuais"; "O passado já passou”, dentre outras, são corriqueiras no ambiente escolar.

$\mathrm{Na}$ perspectiva desses autores, a visão da história factual, pronta e acabada, que relega o sujeito a um papel passivo frente à disciplina, ainda é dominante na educação brasileira. Essa passividade causa problemas, especificamente porque, uma vez que os alunos não se entendem diante dos processos históricos, fica mais difícil à disciplina de História lhes interessar. É justamente quando o ensino entra no campo do desinteresse que surge o grande desafio para a escola e, sobretudo, para os professores, exigindo mudanças rápidas no perfil didático.

Partindo dessa premissa e considerando a realidade cultural dos jovens que frequentam as escolas de ensino fundamental e médio, é possível destacar questões importantes que necessitam ser repensadas, em especial no que se refere ao uso das TDIC no ensino de história.

Já no ano 2000, os Parâmetros Curriculares Nacionais (PCNs) traziam a proposta de utilização de novas metodologias de ensino, além de, naquele 
momento, apontarem para a inevitável transformação que a educação passaria em função da nova compreensão teórica do papel da escola frente à incorporação das novas tecnologias: "É indiscutível a necessidade crescente do uso de computadores pelos alunos como instrumento de aprendizagem escolar, para que possam estar atualizados em relação às novas tecnologias da informação e se instrumentalizarem para as demandas sociais presentes e futuras" (Brasil, 2000, p. 134).

Em 2013, com as Diretrizes Curriculares Nacionais (DCNs), podemos observar não só a constatação da inserção das TDIC como uma realidade, mas também o reforço de seus objetivos enquanto ferramentas educacionais: "devem ser usadas e adaptadas para servir a fins educacionais e como tecnologia assistiva; desenvolvidas de forma a possibilitar que a interatividade virtual se desenvolva de modo mais intenso, inclusive na produção de linguagens". De acordo com o documento, as estruturas tecnológicas, como apoio a atividades pedagógicas na escola, devem estar ancoradas nos diferentes recursos e abertas para a convergência digital (Brasil, 2013, p. 27-28).

Selva Fonseca (2009), em estudos sobre o ensino de História, afirma que "ao incorporar diferentes linguagens no processo de ensino de História, reconhecemos não só a estreita ligação entre os saberes escolares e a vida social, mas também a necessidade de (re)construirmos nosso conceito de ensino e aprendizagem". Ainda segundo essa autora, as metodologias de ensino na atual conjuntura social exigem permanente atualização, constantes investimentos e contínua incorporação de diferentes fontes de conhecimento.

Nesse sentido, propõe-se neste artigo pensar a tecnologia como ferramenta transformadora para o ensino de História, atentando para o fato de que a contribuição metodológica dos diferentes recursos de multimídia, fotografias, vídeos, imagens, sons e filmes, dentre outros, quando usados corretamente, tornam-se ferramenta de alto potencial para a apresentação, construção e transmissão do conhecimento histórico.

Destacando os aspectos do ensino de História, Adelina Moura reafirma a necessidade de ter um ensino em harmonia com nosso tempo: "O uso dos recursos tecnológicos deve estar associado ao domínio de conteúdo e metodologias para que se possa escolher a mais adequada à construção do conhecimento histórico" (Moura, 2009). 
Corroborando Moura (2009), Nucia Oliveira (2012) apresenta uma reflexão sobre o uso das TDIC e, também, sobre sua utilização crítica, apontando para uma renovação no sistema de ensino de história:

É importante entender que a presença de novas linguagens nas aulas de História não deve vir em função de uma simples renovação dos métodos e tampouco pode ser entendida como possibilidade de promover um maior interesse dos estudantes. O importante é conseguir a 'renovação' e mesmo o 'interesse' dos estudantes, articulando para isso uma visão igualmente renovada do ensino de História. (Oliveira, 2012, p. 268)

Considerando o exposto, entende-se a importância do uso das TDIC na prática de ensino de história, sobretudo na renovação de métodos de ensino, que devem caminhar no sentido de despertar o interesse de adolescentes e jovens imersos cada vez mais no mundo digital, onde a velocidade e quantidade da informação vem de forma avassaladora, tornando o ambiente escolar rapidamente obsoleto.

\section{TDIC NA PRÁTICA PEDAGÓGICA: ENTRE RESISTÊNCIAS E POSSIBILIDADES}

De acordo com Alda (2012), a partir da segunda metade do século XX os avanços tecnológicos popularizaram o acesso à informação assegurando a presença das TDIC em grande parte das atividades pós-modernas, ${ }^{2}$ sendo a educação uma delas. Essa inserção, de fato, vem modificando a maneira como a sociedade vive e, consequentemente, a maneira como se constrói o conhecimento.

Por conta dessas mudanças sofridas pela sociedade, faz-se necessário que o docente, assim como o corpo pedagógico, esteja atento, informado e capacitado em relação à inserção das TDIC em planos pedagógicos, objetivando acompanhar as tendências mundiais e tornar o ambiente educacional uma extensão do ambiente quotidiano. Sempre que possível, acrescentando mudanças estruturais na dinâmica de sala de aula, fazendo-a transgredir de um ambiente centrado no docente para um ambiente centrado no aluno. Nessa nova conformação proposta, docentes atuariam como mediadores na busca e construção do conhecimento pelo aluno. 
No aspecto prático-teórico, a abordagem científica que permite fomentar a reflexão sobre o tema proposto tem como base as pesquisas do autor soviético Lev Semenovich Vigotski. ${ }^{3}$ Alicerçada no plano das interações, a teoria vigotskiana é conhecida pela leitura histórico-cultural do desenvolvimento humano, onde o autor traz uma abordagem socioconstrutivista, enfatizando seus aspectos histórico-culturalistas para explicar as relações entre o funcionamento da mente humana e as situações culturais, institucionais e históricas pelas quais esse funcionamento ocorre (Vigotski, 1988).

Castañon (2009), referindo-se à teoria vigotskiana, traduz o conhecimento como um processo de construção social, destacando o fato de o homem transformar e ser transformado com base nas relações de uma determinada cultura. No aspecto prático-teórico, a linha teórica que permite fomentar uma reflexão sobre o tema proposto na presente pesquisa tem como base o interacionismo social de Vigotski (1988).

Neves e Damiani (2006), em estudo sobre Vigotski e as teorias da aprendizagem, afirmam que, do ponto de vista desse autor, o desenvolvimento humano é compreendido não em decorrência de fatores isolados que amadurecem e sim como produto de trocas recíprocas que se estabelecem entre os sujeitos envolvidos e o meio, cada aspecto influenciando o outro. Essa troca de saberes é apontada por alguns autores como ensino híbrido, um conceito novo na literatura educacional que dialoga diretamente com a utilização dos recursos tecnológicos em ambientes educacionais frente à troca de saberes dos sujeitos envolvidos:

O ensino híbrido é um programa de educação formal no qual um aluno aprende, pelo menos em parte, por meio do ensino on-line, com algum elemento de controle do estudante sobre o tempo, lugar, modo e/ou ritmo do estudo, e pelo menos em parte em uma localidade física supervisionada, fora de sua residência. (Christensen et al., 2013, citado por Hoffmann, 2016)

No entanto, pode-se destacar que no grande universo das TDIC encontra-se uma série de ferramentas que ao estarem conectadas aos ambientes educacionais, possibilitam uma maior construção do conhecimento mediado pela interação e pela linguagem (Fey, 2011; Barbosa, 2012).

Segundo Moran, Masetto e Behrens (2009), a tecnologia tem adentrado os ambientes educacionais, atingindo todos os sujeitos envolvidos, criando-se 
assim a expectativa de que as mais recentes tecnologias como internet mais veloz, gráficos interativos e netbooks, entre outras, quando inseridas na sala de aula, apresentariam soluções rápidas para mudar o "problema” educacional. No entanto, a inserção tecnológica, quando não desempenhada de forma inovadora, corre o risco de trazer pouco ou nenhum resultado significativo para o desenvolvimento educacional de cidadãos da atual geração - incluindo-se aqui crianças, jovens, adultos e os idosos (Moran; Masetto; Behrens, 2009).

Além disso, Alda (2012) ressalta que essa inserção é problemática porque a maioria dos docentes são oriundos de formação tradicional, linear, baseada em textos, e que o maior desafio está em romper essas barreiras. Para a autora há uma grande necessidade de letramento digital, ${ }^{4}$ busca por aperfeiçoamento contínuo para adaptação às novas TDIC e para torná-las realmente instrumentos auxiliadores do processo de ensino e aprendizagem em suas práticas pedagógicas.

Considerando essa problemática, analisou-se a faixa etária dos docentes entrevistados, obtendo como resultado sua maior representatividade entre 41 e 50 anos (44\%), conforme o Gráfico 1.

Gráfico 1 - Faixa etária dos docentes entrevistados

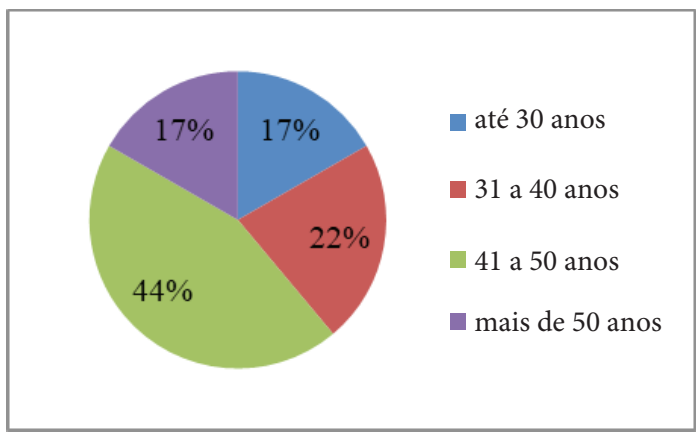

Fonte: Elaboração própria.

Além disso, buscou-se conhecer o tempo de atuação no magistério (Gráfico 2). Constatou-se que a maioria dos docentes (72\%) possui significativa experiência no exercício da profissão, que vai de 10 a 25 anos. Esse fato, somado ao resultado do Gráfico 1, leva a outra reflexão: embora sejam bons conhecedores da profissão, são, em sua maioria, imigrantes digitais, o que faz das tecnologias algo necessariamente "novo" e, acima de tudo, desafiador (Prensky, 2001). 
Gráfico 2 - Anos de experiência no magistério

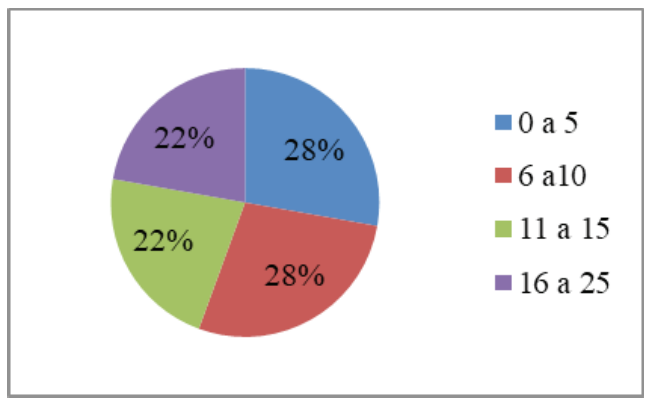

Fonte: Elaboração própria.

Considerando a postura do docente, Nascimento (2012) ressalta que o tempo de serviço pode indicar a consolidação de vínculos estabelecidos no ambiente de trabalho e, em alguns casos, constituir um obstáculo para a implementação de formas inovadoras no modo de lecionar. Além disso, a rotina didática, quando repetida usualmente, pode conduzir o docente à compreensão de que sua prática não precisa necessariamente passar por inovações, podendo também, em contrapartida, levá-lo a incorporar acriticamente qualquer mudança apenas com o intuito de sair da rotina.

Quando questionados sobre sua formação em cursos na área de informática (Gráfico 3), observa-se que mais da metade dos docentes $(61,1 \%)$ possuem curso de Informática Básica.

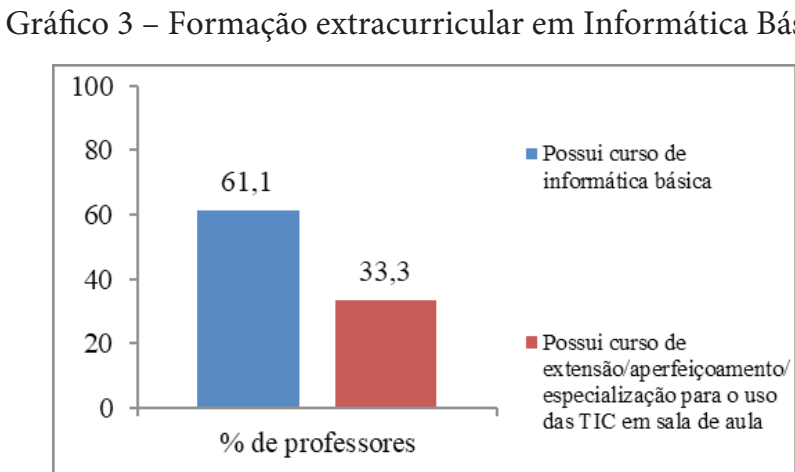

Fonte: Elaboração própria. 
Porém, em relação à formação específica em curso de extensão/aperfeiçoamento ou especialização sobre o uso das TDIC, 66,7\% responderam nunca ter tido nenhum tipo de formação que envolvesse TDIC em ambientes educacionais (Gráfico 4).

Gráfico 4 - Cursos para o uso das TDIC na sala de aula

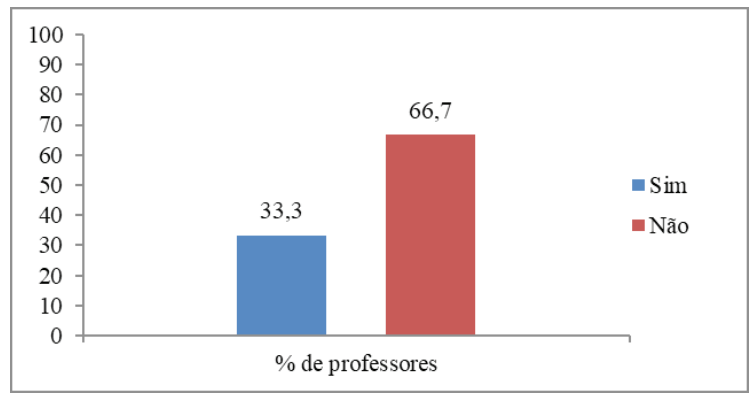

Fonte: Elaboração própria.

Esse é um fato relevante e aponta para uma grande demanda de políticas públicas voltadas para capacitação e especialização dos docentes em exercício do magistério nas instituições.

Clésia Santana corrobora os resultados aqui apresentados quando em seu trabalho "A incorporação das TIC nas escolas: desafios contemporâneos" (Santana, 2011) aponta para uma necessária mudança na prática do docente, que deverá ser impulsionada por uma formação que lhe oportunize, além do acesso ao meio de comunicação, a interação com seus pares no desenvolvimento de experiências inovadoras que busquem apropriar-se do uso das TDIC. Caso contrário, a incorporação das TDIC em ambientes educacionais se revelará apenas um verniz de modernidade, em uma tentativa de camuflar marcas de práticas pedagógicas tradicionais e muitas vezes desassociadas de sentido no processo de ensino e aprendizagem (Santana, 2011).

De acordo com Miranda (2007), "se o docente dominar estas novas ferramentas poderá apoiar os alunos a explorar as potencialidades destes novos sistemas de tratamento e representação da informação". No entanto, cabe ressaltar que a utilização das novas tecnologias dentro da perspectiva pedagógica não se restringe apenas à manipulação de determinados equipamentos e produtos; ela altera comportamentos, impõe-se à cultura existente, transformando 
não apenas o comportamento individual do educando, mas toda a natureza social do ambiente educacional (Kenski, 2007).

Todos os docentes responderam possuir computador com acesso a internet em sua residência, e um dado relevante é que 94,5\% declararam utilizá-lo para fins pedagógicos (Gráfico 5).

Gráfico 5 - Acesso ao computador e seu uso

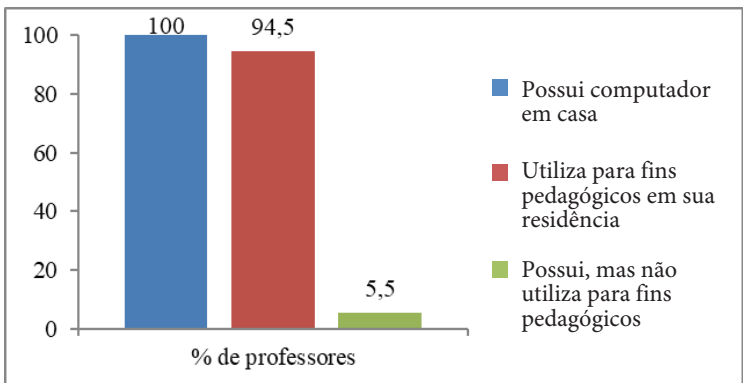

Fonte: Elaboração própria.

Esse dado revela possibilidades de inúmeras formas de acesso a pesquisas na área de educação, por parte dos docentes.

Outra questão abordada foi o acesso ao laboratório de informática durante a formação como docente. Apenas $44,4 \%$ dos profissionais entrevistados afirmam ter tido acesso a ele. Esse dado é relevante, tendo em vista que menos da metade dos docentes entrevistados não tiveram acesso, durante sua formação, a recursos como laboratório de informática. De acordo com Girardi (2011), o educador na era da informação tem de enfrentar os paradigmas ultrapassados que a envolvem, assim como encontrar caminhos próximos ao momento histórico em que vive.

Em relação às escolas onde os docentes trabalham, 71\% delas possuem laboratório de informática, mas somente $57 \%$ deles encontram-se ativos.

Em relação à utilização do laboratório de informática pelos docentes entrevistados, 27\% declararam utilizar o laboratório de informática, e o Gráfico 6 descreve a forma como esses docentes utilizam o laboratório. 
Gráfico 6 - Forma como os docentes utilizam o laboratório de informática

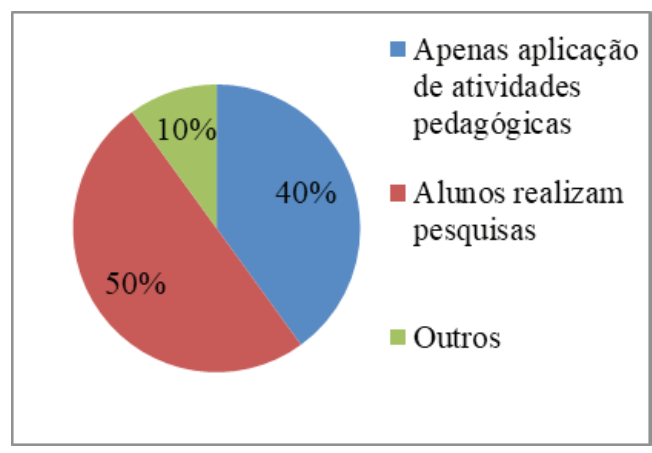

Fonte: Elaboração própria.

Um dado que chamou a atenção durante a análise do Gráfico 6 foi o baixo número de docentes de História que utilizam o laboratório de informática da escola. Assim, buscou-se levantar os motivos desse resultado negativo. Para tanto, destacou-se a fala dos dez docentes que responderam. As falas foram codificadas pela letra " $\mathrm{D}$ " e por números sequenciais (D1: docente 1; D2: docente 2 ; etc.), indicando qual profissional respondeu a pesquisa.

Ao perguntar: "Caso não utilize, justifique", os docentes responderam:

Falta de técnicos:

$<$ D1> "O técnico quase não se encontra nos meus dias e horários";

$<$ D2> "O laboratório encontra-se trancado por falta de funcionário";

$<$ D3 $>$ "O técnico responsável foi transferido, então os docentes não utilizam mais".

Laboratórios em reforma:

$<$ D4> "Ainda não foi concluído";

$<$ D5> "Está em reforma, por isso os docentes não estão utilizando".

Laboratórios desativados:

$<$ D6> "Existe uma sala com algumas máquinas, mas está desativada desde 2010";

$<$ D7> "Não está disponível". 


\section{Outras razões:}

$<$ D8 > "Pouco funciona, e o interesse dos alunos é só buscar futilidade";

$<$ D9> "A internet é lenta, e a disponibilidade de computadores é insuficiente";

$<$ D10> "A escola não possui laboratório de internet".

Como podemos observar nas respostas, o não uso do laboratório de informática relaciona-se à insegurança do docente em sua operação. Percebeu-se desde uma possível resistência de profissionais mais tradicionais, tidos como imigrantes ou até mesmo excluídos digitais, choque de gerações em função da maior facilidade dos jovens em lidar com a tecnologia, e até mesmo a uma real necessidade de capacitação constante dos profissionais ligados à educação, por meio do poder público responsável pelos estabelecimentos.

Tal fato é corroborado pelas falas dos docentes $\langle$ D $1>$ e $\langle$ D 3$\rangle$, quando sentem a necessidade de apoio técnico. Além disso, é possível verificar uma das questões mais sérias envolvendo a prática pedagógica com uso de tecnologias: a manutenção e modernização de máquinas e salas de informática, conforme relatado nas falas $\langle$ D6 $>$, $<$ D8 $>$ e $<$ D9 $>$ quando mencionam que "quase não funciona".

De acordo com dados do Censo Escolar 2010, 60,45\% das escolas brasileiras possuem computador. Cerca de $70 \%$ das que atendem ao Ensino Fundamental II ( $6^{\circ}$ ao $9^{\mathrm{a}}$ ano) têm acesso à internet, porém, somente $23 \%$ das escolas urbanas contam com manutenção preventiva, corroborando o que foi informado pelos docentes a respeito da falta de manutenção.

Outro ponto de igual importância a ser destacado se refere à condição estrutural da escola. Os dados coletados apontam que apenas $36,21 \%$ das escolas apresentam laboratório de informática ativo, além da questão da ausência de conexão com a internet, que limita o aproveitamento pedagógico no caso das escolas que possuem recursos tecnológicos. Essa situação é grave, considerando que a implantação adequada dos recursos tecnológicos é condição fundamental para o desenvolvimento eficiente do uso pedagógico das TDIC nos espaços educacionais. Esses fatores, dentre outros, contribuem em grande parte para a não inserção dos recursos tecnológicos nas práticas pedagógicas dos docentes entrevistados. 
Dando continuidade aos questionários, ao serem consultados sobre a presença de projetor multimídia, $66,6 \%$ dos entrevistados declaram que suas escolas estão equipadas com o aparelho. Sobre a utilização e dificuldade de uso do projetor multimídia pelos docentes, de acordo com o resultado dos questionários, $50 \%$ dos professores entrevistados declaram utilizar o aparelho em sala de aula, e desses que o utilizam, $28 \%$ o fazem com dificuldade.

Os dados coletados apontam para o fato de que, mesmo com as tecnologias presentes nas escolas, há certa dificuldade em seu uso. Curiosamente, quando se indagou sobre a justificativa para a dificuldade em utilizar o projetor multimídia, apenas $22,2 \%$ dos $66,6 \%$ docentes que afirmam ter projetor nas escolas em que atuam responderam à questão.

$\mathrm{Na}$ fala dos docentes as justificativas encontradas foram:

$<$ D1 > "Preciso do auxílio do técnico, mas ele nunca está;

$<$ D2> "[...] ainda não foi viabilizada a famosa sala de multimídia. Esse é o motivo da não utilização do recurso";

$<$ D3> "A escola não possui um computador portátil para esse fim";

$<$ D4> "Tenho dificuldade quanto ao som (dos vídeos e músicas). Nem sempre posso usar a caixa de som".

Estas falas levam a inferir o despreparo das instituições para inserção, assim como para a própria utilização das TDIC como ferramentas tecnológicas colaboradoras no processo de ensino. Percebe-se ainda, a falta que faz a capacitação para o seu uso no dia a dia da prática docente.

Para contribuir com essa reflexão, procuraram-se indicadores que permitissem compreender a integração das TDIC no processo de ensino e aprendizagem dos docentes de História. Em relação aos dados coletados (Gráfico 7), a análise buscou levantar quais as tecnologias utilizadas pelos docentes de História na sala de aula. 
Gráfico 7 - Tipos de Tecnologias da Informação e Comunicação (TDIC) utilizadas como ferramenta pedagógica em sala de aula

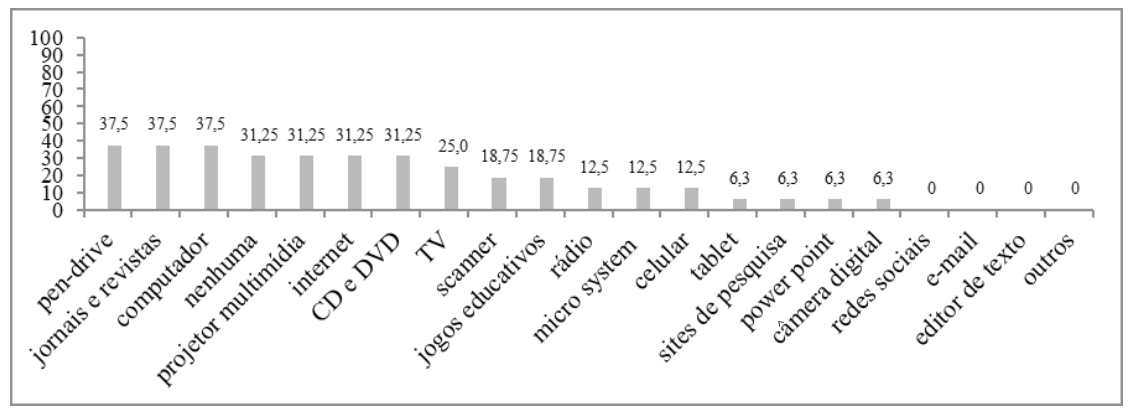

Fonte: Elaboração própria.

Como se pode observar, tecnologias como computador, projetor multimídia, pen-drive, CD/ DVD, internet e até mesmo jornais e revistas apresentam-se como recursos mais comuns para utilização pelos docentes. Nota-se que ferramentas como celulares, enquanto tecnologias móveis, redes sociais, jogos educativos, softwares e sites de pesquisas não estão entre os recursos frequentemente utilizados, embora estejam muito presentes na realidade cultural de grande parte dos alunos. Os dados aqui expostos permitem observar que, embora haja a utilização de diversas tecnologias nos ambientes educacionais, elas se apresentam de forma pouco representativa considerando a baixa frequência de utilização, ou mesmo a não utilização de algumas. A utilização das TDIC variou de $6,25 \%$ a $37,2 \%$, considerando a variação dos recursos tecnológicos.

No que se refere às tecnologias móveis como celulares e tablets, com exceção dos docentes que declaram utilizá-las em sua prática, os demais, além de não utilizarem, também não demonstram nenhum interesse em integrá-las à sua prática docente. Muitos, aliás, demonstram dificuldade em compreender tais ferramentas como possíveis recursos facilitadores do processo de ensino, como descrito mais adiante.

De acordo com Oliveira e Medina, a utilização de tecnologias móveis em ambientes educacionais apresenta-se como facilitador do processo de ensino por permitir maior versatilidade de acesso ao conteúdo em qualquer lugar e a qualquer hora. De acordo com os autores, no caso do celular, por ser um 
aparelho bem difundido e relativamente acessível, permite que estudantes de diferentes classes sociais tenham acesso mais fácil a conteúdos educacionais (Oliveira; Medina, 2007).

Os dados apresentados no Gráfico 8 se referem apenas à utilização de tais recursos em sala de aula, e não à sua aplicação efetiva em termos de planejamento, tipos de métodos desenvolvidos para utilização, direcionamento do planejamento ou tempo de condução, dentre outros fatores.

Gráfico 8 - Tipos de Tecnologias da Informação e Comunicação (TDIC) que os docentes gostariam de utilizar como ferramenta pedagógica em sala de aula

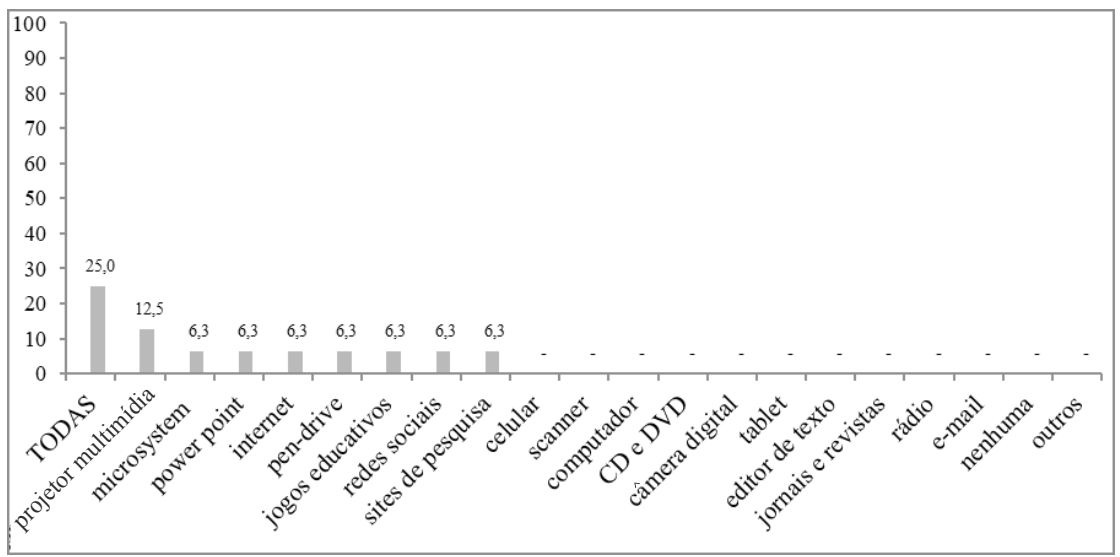

Fonte: Elaboração própria.

Como podemos observar no Gráfico 8, os docentes que responderam não utilizar nenhuma TDIC na sala de aula demonstram interesse não apenas em suportes como microsystem, pen-drive, projetor multimídia, mas também em sites de pesquisas, jogos educativos e redes sociais.

Seguindo a análise, quando questionados sobre o conhecimento acerca de algum software educativo, apenas cinco docentes dos 18 que responderam ao questionário declaram conhecer e utilizar. Porém, quando se solicitou que citassem os softwares utilizados, mencionam sites como wikipédia, google, prezi e superpro, dentre outros, que obviamente não representam softwares educacionais na área de História. Esse resultado expõe claramente o problema da inserção das tecnologias na educação hoje, caracterizada por ocorrer de forma 
verticalizada, sem a devida capacitação dos docentes. Tal fato faz ainda mais sentido quando contrastado com os dados sobre capacitação, pois apenas $33,3 \%$ dos docentes entrevistados alegaram possuir algum curso de especialização/extensão ou aperfeiçoamento voltados à utilização das TDIC em sala de aula, como já descrito anteriormente. Essa baixa participação impede o acesso às TDIC para que desenvolvam as boas práticas que os cursos de formação continuada oferecem.

De acordo com Santana (2011), as TDIC tornaram-se fator relevante na formação do profissional da educação por contribuírem para um maior desenvolvimento do aprendizado significativo, proporcionando aulas motivadoras, além de ampliarem e intensificarem sua capacidade de aprendizagem. Logo, o potencial para o desenvolvimento educacional, assim como o avanço em direção à utilização das TDIC em ambientes educacionais, apresentam-se de forma muito distinta, confrontando com a demanda de políticas públicas que não só estimulem a adoção de tecnologias com foco na aprendizagem dos alunos, mas promovam formação específica e continuada que capacite os docentes para melhor lidar com elas.

Nesse sentido, ressalta-se que o acesso às tecnologias móveis, tão presentes no cotidiano dos alunos, leva cada vez mais os educadores do século XXI a terem de se adequar ao "novo". De acordo com Adelina Moura (2009): "O acesso a conteúdos multimídia deixou de estar limitado a um computador pessoal e estendeu-se também às tecnologias móveis, proporcionando um novo paradigma educacional, através da aprendizagem móvel”.

Questionados sobre o uso de tecnologias móveis pelos alunos, 100\% dos docentes identificaram o uso por parte dos alunos durante a sua aula. No entanto, a maioria dos docentes entrevistados, embora conheçam esses recursos, não os veem como instrumentos facilitadores no que se refere à mediação do conteúdo, posto que $34 \%$ dos entrevistados o categorizaram como competidor e 33,3\% como um grande obstáculo para o processo de ensino e aprendizado durante a aula. Dessa forma, somados ao percentual que o considera indiferente, pode-se considerar que 78,3\% dos docentes não vislumbram possibilidades que as tecnologias móveis podem desempenhar no enriquecimento do conteúdo dentro de sala de aula.

De acordo com Nascimento (2012), existe uma significativa diferença em relação à forma pela qual os alunos usam as tecnologias para se comunicar no 
dia a dia e como eles as usam nas escolas. De acordo com a autora, essas tecnologias muitas vezes consideradas como instrumentos lúdicos, são essenciais para a comunicação dos alunos com o mundo. No entanto, os ambientes educacionais estão demorando a reconhecer os benefícios que esses instrumentos podem trazer para a educação. Nesse contexto, as DCNs apontam para a mesma direção:

Essa distância necessita ser superada, mediante aproximação dos recursos tecnológicos de informação e comunicação, estimulando a criação de novos métodos didático-pedagógicos, para que tais recursos e métodos sejam inseridos no cotidiano escolar. Isto porque o conhecimento científico, nos tempos atuais, exige da escola o exercício da compreensão, valorização da ciência e da tecnologia desde a infância e ao longo de toda a vida, em busca da ampliação do domínio do conhecimento científico: uma das condições para o exercício da cidadania. (DCNs, 2013, p. 25-26)

Göttsche (2012) coloca que, "a maior parte das escolas ainda não se adaptou a um contexto social diferente, com novas formas de comunicação, de ensino e de trabalho, um contexto com redes sociais e tecnologias móveis". Ainda segundo o autor, as tecnologias móveis apresentam-se, sobretudo, para os jovens como especialmente adequadas as suas necessidades e usos individuais, o que por sua vez amplia a capacidade de aprender com este gênero de tecnologia (Göttsche, 2012).

Para finalizar, questionou-se aos docentes quais conhecimentos seriam necessários para fazerem uso das TDIC nas escolas de forma a contribuir para a aprendizagem significativa dos alunos. Dos 18 professores entrevistados, 13 responderam ao questionamento.

Abaixo, as falas dos entrevistados:

$<$ D1> "Conhecimento sobre informática educativa e de software de sua disciplina";

$<$ D2> "Deve-se conhecer antes os aplicativos para depois utilizá-los na sala de aula. Deve-se conscientizar os alunos do bom uso das tecnologias";

$<$ D3> "Desenvolvimento de práticas pedagógicas para o uso destas tecnologias a favor da aprendizagem";

$<$ D4> "Um curso de capacitação, técnico disponível na escola e etc."; 
$<$ D5 $>$ "Primeiro tem que ser tecnologia direcionada pelo docente e que tenha sentido e relacionado de alguma maneira com o conteúdo da aula (isso é fácil, é só planejar), nessa disciplina temos que exemplificar fenômenos sociais - ex: Guerra é guerra, o que muda são as motivações e as armas mais destruidoras e etc.";

$<$ D6> "Formação em cursos de informática prática";

$<$ D7> "Curso preparatório, contando que o docente saia da sala de aula durante o curso, facilitando o aprendizado do docente";

<D8> "É necessário desenvolver competência em informação. 1-busca e pesquisa na rede. 2-familiaridade com software e sistemas de informação";

<D9> "Conhecimento (tecnológico)".

$<$ D10 $>$ "Oferta de cursos para professores"

$<$ D11 $>$ "Conhecimento sobre informática educativa"

$<$ D12> "Saber fazer uso das novas tecnologias"

Ressalta-se a resposta do docente: $<$ D13 > "É incompatível, um motor de Ferrari num fusca velho", sinalizando bem o verniz de modernidade como tentativa de camuflar marcas de práticas pedagógicas já ultrapassadas e pouco atraentes, conforme Santana (2011) lembra em seus escritos já mencionados.

\section{CONSIDERAÇÕES FINAIS}

O presente trabalho buscou aferir junto aos professores de História do ensino fundamental II suas percepções quanto a utilização pedagógica das TDIC, além de apontar alguns desafios e dificuldades frente a utilização das mesmas. Pode-se observar na análise dos dados coletados que um dos pontos mais desafiadores na utilização das TDIC em ambientes educacionais está relacionado à implantação de uma cultura digital nas práticas pedagógicas, tendo em vista que grande parte dos docentes entrevistados apresenta resistência em relação ao uso das TDIC em sala de aula, sobretudo, pelo fato de se sentirem despreparados. 
Isto posto, considera-se de grande importância a integração das TDIC na formação inicial docente através de mudanças na prática de ensino e do próprio modelo curricular. É necessário que as instituições de ensino estejam preocupadas em formar professores para o século XXI, aptos a lidar criticamente com as sucessivas transformações do conhecimento, e, além disso, que as unidades escolares estejam equipadas com salas de recursos tecnológicos atuais e em pleno funcionamento, sem, contudo, que se considerar o uso de tecnologias individuais móveis como prática docente.

No que se refere aos resultados encontrados, a falta de manutenção das salas de informática apresenta-se como um outro complicador, onde parte dos professores que demostram ter certa afinidade com os novos recursos tecnológicos deparam-se com uma escola sem estrutura e pouco preparada, tornando, na maioria das vezes impraticável a sua inserção. Um fator positivo é que, apesar das dificuldades enfrentadas mediante a inserção de novas tecnologias digitais em sala de aula, prevalece na soma das opiniões e comentários uma visão favorável ao uso das TDIC, pois a maioria dos que não as utilizam, gostariam de utilizá-las em sala de aula.

Essa problemática levantada demanda, certamente, a construção de uma agenda de planejamento que atenda a curto, médio e longo prazo às demandas socioeducacionais, onde a inserção das TDIC deve apresentar-se como uma política de Estado, em que não só se assuma o financiamento da política e cobertura das ações, mas, sobretudo, que crie métodos de definição de modelo de integração das TDIC a serem implantadas e de atuação continuada. O professor não pode, de forma alguma, estar sozinho neste desafio que é, por si só, um desafio institucional e de interesse público nacional.

Portanto, é preciso ir além e pensar o Estado como um ator insubstituível na condução de políticas que visem à implantação das TDIC em ambientes educacionais. É necessário que as instituições de ensino estejam preocupadas em formar professores para o século XXI, aptos a lidar criticamente com as sucessivas transformações do conhecimento e, acima de tudo, usá-las a seu favor para que enfim, comecemos a romper com a distância entre nativos e imigrantes digitais, tornando o processo de ensino aprendizado de história mais rico, interessante e dentro da realidade dos alunos. É sabido que passos importantes nesse sentido têm sido dados, porém é preciso ampliá-los e democratizá-los. 


\section{REFERÊNCIAS}

ALDA, Lúcia Silveira. Novas tecnologias, novos alunos, novos docentes: refletindo sobre o papel do docente na contemporaneidade. In: SEMINÁRIO INTERNACIONAL DE LETRAS: LÍNGUA E LITERATURA NA PÓS-MODERNIDADE, 2012, Rio Grande do Sul. Anais... Santa Maria: Unifra, 2012, v. 2, s. p. Disponível em: http://www.unifra.br/eventos/inletras2012/Trabalhos/4668.pdf. Acesso em: 20 fev. 2013.

BARBOSA, Cláudia Maria A. M. A aprendizagem mediada por TIC: interação e cognição em perspectiva. Revista Brasileira de Aprendizagem Aberta e a Distância, São Paulo: ABED, n. 11, p. 83-100, 2012. Disponível em: http://www.abed.org.br/revistacientifica/revista_pdf_doc/2012/artigo_07_v112012.pdf. Acesso em: 20 fev. 2013.

BRASIL. Ministério da Educação. Parâmetros Curriculares Nacionais para o Ensino Fundamental. Brasília: MEC, 2000.

BRASIL. Ministério da Educação. Secretaria de Educação Básica. Secretaria de Educação Continuada, Alfabetização, Diversidade e Inclusão. Conselho Nacional de Educação. Diretrizes Curriculares Nacionais da Educação Básica. Brasília: MEC/ SEB/DICEI, 2013.

CAIMI, Flávia Eloisa. Cultura, memória e identidade: o ensino de história e a construção de discursos identitários. In: BERETA, Cristiane; ZAMBONI, Ernesta (org.). Ensino de História, memória e cultura. Curitiba: CRV, 2013.

CARMO, Josué Geraldo B. do. O letramento digital e a inclusão social. 2003. Disponível em: http://www.educacaoliteratura.com/index\%2092.htm. Acesso em: 22 jun. 2017.

CASTAÑON, Gustavo A. Construtivismo social: a ciência sem sujeito e sem mundo. 2009. Dissertação (Mestrado em Filosofia) - Programa de Pós-graduação em Lógica e Metafísica, Universidade Federal do Rio de Janeiro (UFRJ). Rio de Janeiro, 2009. Disponível em: https://ppglm.files.wordpress.com/2008/12/dissertacao-ppglm-gustavo-arja-castanon.pdf. Acesso em: 3 mar. 2013.

CHRISTENSEN, Clayton et al. Ensino Híbrido: uma inovação disruptiva? Clayton Christensen Institute, 2013. Disponível em: https://portalrevistas.ucb.br/index. php/raead/article/view/7517/4651. Acesso em: 18 mar. 2016.

DAMASCENO, José Alves; BRITO, Glaucia da Silva. O uso das TICs nas aulas de história e estratégias para inclusão digital dos professores. Programa de desenvolvimento Educacional, 2009. Disponível em: http://www.diaadiaeducacao.pr.gov.br/ portals/pde/arquivos/1414-8.pdf. Acesso em: 9 mar. 2013.

FEY, Ademar Felipe. A linguagem na interação docente-aluno na era digital: considerações teóricas. Revista Tecnologias na Educação, v. 3, n. 1, s. p., 2011. Disponível em: http://tecedu.pro.br/wp-content/uploads/2015/07/Art1-ano3-vol-4julho2011.pdf. Acesso em: 2 fev. 2013. 
FONSECA, Selva Guimarães. Didática e prática de ensino de História: experiências, reflexões e aprendizados. 8. ed. Campinas: Papirus, 2009.

GIRARDI, Solange Campelo. A formação de docentes acerca de novas tecnologias na educação. 2011. Monografia (Licenciatura em Ciências Biológicas) - Consórcio Setentrional de Educação a Distância, Universidade de Brasília (UnB), Universidade Estadual de Goiás (UEG). Brasília, 2011. Disponível em: http://bdm. unb.br/bitstream/10483/1776/1/2011_SolangeCampeloGirardi.pdf. Acesso em: 15 dez. 2013.

GÖTTSCHE, Katja. Tecnologias móveis: uma mais valia em contextos educacionais? Revista Linhas, Florianópolis, v. 13, n. 2, p. 62-73, 2012. Disponível em: http:// www.revistas.udesc.br/index.php/linhas/article/view/198472381302201 2062/2134. Acesso em: 15 dez. 2013.

HOFFMANN, Elíria Heck. Ensino híbrido no ensino fundamental: possibilidades e desafios. 2016. Projeto de trabalho de conclusão de curso (Especialização em Educação na Cultura Digital) - Universidade Federal de Santa Catarina (UFSC). Florianópolis, 2016.

IBGE. Censo Demográfico 2010. Disponível em: http://www.Censo2010.ibge.gov.br. Acesso em: $10 \mathrm{dez} .2013$.

IDEB 2011. (Índice de Desenvolvimento da Educação Básica). Brasília: Inep/MEC, 2011.

KARNAL, Leandro (org.). História na sala de aula: conceitos, práticas e propostas. São Paulo: Contexto, 2004.

KENSKI, Vani Moreira. Educação e tecnologias: o novo ritmo da informação. Campinas: Papirus, 2007.

LIMA, Ana Lúcia D’Império. Uso das TIC na Educação: inclusão digital ou exclusão digital? In: PESQUISA sobre o uso das tecnologias de informação e comunicação no Brasil [livro eletrônico]: TIC Educação, 2012.

MATTOS, Matheus Carvalho de; SOUZA, Carlos Henrique M. de; MANHÃES, Fernanda Castro. A dromocracia cibercultural nas redes sociais digitais. InterSciencePlace, Revista Científica Internacional, v. 1, n. 21, p. 178-196, 2012.

MIRANDA, Guilhermina L. Limites e possibilidades das TIC na educação. Sísifo, Revista de Ciências da Educação, n. 3, p. 41-50, 2007.

MORAN, José Manuel; MASETTO, Marcos T.; BEHRENS, Marilda Aparecida. Novas tecnologias e mediação pedagógica. 13. ed. Campinas: Papirus, 2009.

MOURA, Adelina. Geração Móvel: um ambiente de aprendizagem suportado por tecnologias móveis para a "Geração Polegar". In: CONFERÊNCIA INTERNACIONAL DE TIC NA EDUCAÇÃO, 6., 2009, Braga. Actas... Braga: Universidade do Minho, Portugal. p. 55-78. 
MOURA, Mary Jones F. de. O ensino de História e as novas tecnologias: da reflexão à ação pedagógica. In: SIMPÓSIO NACIONAL DE HISTÓRIA E ÉTICA, 25., 2009, Fortaleza. Anais... Fortaleza: Ed. UFC, 2009. p. 1-10.

NADAI, Elza. A escola pública contemporânea: os currículos oficiais de história e o ensino temático. In: NADAI, Elza. FENELON, Déa R. (org.). Revista Brasileira de História, São Paulo: Anpuh: Marco Zero, v. 6, n. 11, p. 99-116, 1996.

NASCIMENTO, Ana Cristina T. A. A integração das tecnologias às práticas escolares. In: PESQUISA sobre o uso das tecnologias de informação e comunicação no Brasil [livro eletrônico]: TIC Educação, 2012. p. 45-50.

NEVES, Rita de Araújo; DAMIANI, Magda Floriana. Vygotsky e as teorias da aprendizagem. UNIrevista, v. 1, n. 2, p. 1-10, 2006.

NUNES, Ivônio Barros. A história da EaD no mundo. In: LITTO, Fredric M.; FORMIGA, Marcos (org.). Educação a Distância: o estado da arte. São Paulo: Pearson, 2009. p. 2-8.

OLIVEIRA, Leandro R. de; MEDINA, Roseclea D. Desenvolvimento de objetos de aprendizagem para dispositivos móveis: uma nova abordagem que contribui para a educação. Novas tecnologias na educação, v. 5, n. 1, p. 1-11, 2007. Disponível em: www.seer.ufrgs.br/renote/article/download/14154/8089. Acesso em: 10 nov. 2013.

OLIVEIRA, Nucia A. S. de. "Novas" e "diferentes" linguagens e o ensino de história: construindo significados para a formação de professores. EntreVer, Florianópolis, v. 2, n. 2, p. 262-277, jan./jun. 2012.

ORIÁ, Ricardo. O negro na historiografia didática: imagens, identidades e representações. Textos de História, v. 4, n. 2, p. 154-165, 1993.

PORTO, Tania Maria E. As tecnologias de comunicação e informação na escola: relações possíveis... relações construídas. Revista Brasileira de Educação, v. 11, n. 31, p. 43-57, 2006.

PRENSKY, Marc. Nativos digitais, imigrantes digitais. Trad. Roberta M. Souza. Título original: Digital natives, digital immigrants. Publicado em: On the Horizon, NCB University Press, v. 9, n. 5, 2001. Disponível em: www.colegiongeracao.com.br/novageracao/2_intencoes/nativos.pdf. Acesso em: 10 nov. 2013.

ROSA, Rosemar. Trabalho docente: dificuldades apontadas pelos docentes no uso das tecnologias. In: ENCONTRO DE PESQUISA EM EDUCAÇÃO, 7.; CONGRESSO INTERNACIONAL TRABALHO DOCENTE E PROCESSOS EDUCATIVOS, 2.; SIMPÓSIO DE ÉTICA EM PESQUISA, 2., 2013, Uberaba, MG. Anais... Uberaba: Universidade de Uberaba, 2013. p. 214-227.

SANFELICE, José Luis. Pós-modernidade, globalização e educação. In: LOMBARDI, José Claudinei (org.). Globalização, pós-modernidade e educação: história, filosofia e temas transversais. Campinas: Autores Associados: HISTEDBR; Caçador, SC: UnC, 2001. 
SANTANA, Clésia Maria. A incorporação das TIC nas escolas: desafios contemporâneos. In: ENCONTRO DA ASSOCIAÇÃO NACIONAL DE POLÍTICA E ADMINISTRAÇÃO EM EDUCAÇÃO - ANPAE, 6., 2011, s. 1.

SANTOS, Marisilvia dos; SCARABOTTO, Suelen do Carmo dos A.; MATOS, Elizete Lucia M. Imigrantes e nativos digitais: um dilema ou desafio na educação? In: CONGRESSO NACIONAL DE EDUCAÇÃO (EDUCERE), 10., 2011, Curitiba. Anais... Paraná: Ed. PUC-PR, 2011. p. 40-51.

SOUZA, Carlos Henrique M. de. Tecnologias e novos modos de comunicação: (re) invenção do conhecimento. Revista Electrónica Internacional de Economía Política de las Tecnologías de la Información y la Comunicación, v. 11, n. 1, p. 1-13, 2009.

VIGOTSKI, L. S. A formação social da mente: o desenvolvimento dos processos psicológicos superiores. 6. ed. São Paulo: Martins Fontes, 1988.

\section{NOTAS}

${ }^{1}$ Nativos digitais seriam os indivíduos que nasceram e cresceram em meio aos avanços tecnológicos, ou seja, os alunos; já os imigrantes digitais seriam aqueles que nasceram em um período anterior e sofreram em sua geração mudanças tecnológicas bruscas.

${ }^{2}$ Fredric Jameson citado por SANFELICE (2001): “A pós-modernidade entendida como sinal cultural de um novo estágio da história do modo de produção reinante: assinala-se a explosão tecnológica da eletrônica moderna e seu papel como principal fonte de lucro e inovação...”.

${ }^{3}$ Levando-se em consideração as diferentes formas de escrita do nome do estudioso russo Lev Semenovich Vygotsky (1896-1934) - Vygotsky, Vigotsky, Vygotski, Vigotskii, Vigotski, entre outras -, adotaremos Vigotski (como grafado pela editora Martins Fontes), exceto em eventuais referências bibliográficas.

${ }^{4}$ De acordo com CARMO (2003) o letramento digital corresponde a habilidades para construir sentido a partir de textos multimodais, isto é, textos que mesclam palavras, elementos pictóricos e sonoros numa mesma superfície. Inclui também a capacidade para localizar, filtrar e avaliar criticamente informações disponibilizadas eletronicamente.

Artigo recebido em 22 de abril de 2017. Aprovado em 5 de março de 2018. 